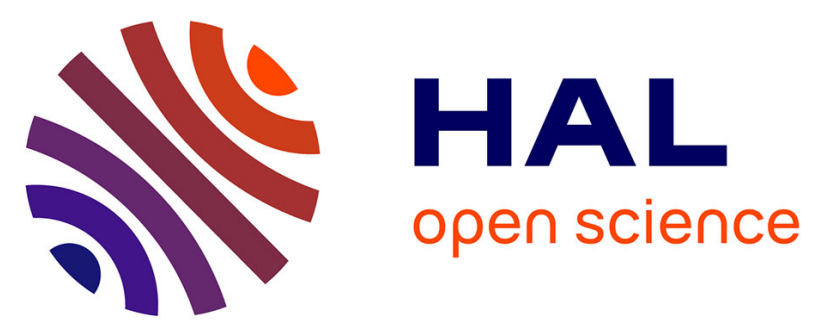

\title{
Hierarchical chirality expression of gemini surfactant aggregates via equilibrium between chiral nucleotide and nonchiral mono-anions
}

Dmytro Dedovets, Barbara Martin, Yutaka Okazaki, Thierry Buffeteau, Emilie Pouget, Reiko Oda

\section{To cite this version:}

Dmytro Dedovets, Barbara Martin, Yutaka Okazaki, Thierry Buffeteau, Emilie Pouget, et al.. Hierarchical chirality expression of gemini surfactant aggregates via equilibrium between chiral nucleotide and nonchiral mono-anions. Chirality, 2020, 32 (7), pp.949-960. 10.1002/chir.23230 . hal-03016432

\section{HAL Id: hal-03016432 \\ https://hal.science/hal-03016432}

Submitted on 20 Nov 2020

HAL is a multi-disciplinary open access archive for the deposit and dissemination of scientific research documents, whether they are published or not. The documents may come from teaching and research institutions in France or abroad, or from public or private research centers.
L'archive ouverte pluridisciplinaire $\mathbf{H A L}$, est destinée au dépôt et à la diffusion de documents scientifiques de niveau recherche, publiés ou non, émanant des établissements d'enseignement et de recherche français ou étrangers, des laboratoires publics ou privés. 


\title{
Hierarchical chirality expression of gemini surfactant aggregates via equilibrium between chiral nucleotide and non-chiral mono-anions
}

\author{
Dmytro Dedovets, ${ }^{1,2}$ Barbara Martin, ${ }^{1}$ Yutaka Okazaki, ${ }^{1,3}$ Thierry Buffeteau, ${ }^{4}$ Emilie Pouget, ${ }^{*, 1}$ \\ Reiko Oda*,1
}

\begin{abstract}
The assembling behaviors of non-chiral dicationic amphiphilic molecules (gemini) in the presence of the mixture of chiral anionic nucleotides and non-chiral anions are investigated. We demonstrate that subtle balance of various physico-chemical parameters and the competition between
\end{abstract}

chiral and non-chiral anions at the interface of gemini assemblies influences the expression of molecular chirality at the micrometer scale through the hierarchical molecular assembly.

Keywords: Self-assembly, chirality, guanosine-5'-monophosphate, nucleo amphiphiles, gemini surfactant, micrometric helices

\section{Introduction}

Self-assembly is the basis for many unique living and natural processes including protein folding and the formation of cell membranes, the process of which is governed by complex cooperative inter- and intramolecular forces that include hydrophobic effect, hydrogen bonding, electrostatic interactions, metal coordination, $\pi-\pi$ interactions and van der Waals forces. Chirality plays an important role in the complexity of these structures and functions from the molecular level as observed for the right-handed $\alpha$-helical structures of proteins or the double helical DNA, to supramolecular hierarchical structures.

Scientists developed wide range of bio-inspired artificial helical molecules, oligomers, polymers or helical assemblies from small molecules. The aggregation of chiral molecules and the hierarchical formation of chiral structures such as twisted or helical ribbons constitute an important domain of research for which the first report can already be found in $1952 .^{1,2}$

Since then, and particularly from the latter half of the 80 , the number of the reports on the self-assembled chiral structures increased exponentially, including several important review articles and books. ${ }^{3-6}$ Most of these systems were designed based on molecules having chiral moieties such as peptidic, lipidic, nucleotidic, or sugar based entities ${ }^{7-12}$ and show nanometer-scale helical structures. Interestingly, only limited number of studies reported self-assembly of micrometric chiral structures from molecules ${ }^{11,13-19}$

Previously, we reported the synthesis and characterization of the self-assemblies from non-chiral monocationic surfactant having two hydrophobic chains of 12 and 14 carbons $\left(\left(\mathrm{C}_{12}\right)_{2}{ }^{+}\right.$and $\left.\left(\mathrm{C}_{14}\right)_{2}{ }^{+}\right)$, complexed with guanosine-5'-monophosphate (GMP) and adenosine 5'monophosphate (AMP)..$^{20-22}$ With both $\left(\mathrm{C}_{12}\right)_{2} \mathrm{GMP}$ and $\left(C_{14}\right)_{2}$ AMP monocationic surfactants stoichiometric complexes, coexistence of micrometric helices with needle-like structures was observed. While the intermolecular interaction between chiral anionic nucleotides is crucial for the chirality transfer and amplification, too strong interaction may lead to crystallization or aggregation without chirality expression. In parallel, our other studies of peptide-based amphiphilic molecular assemblies which showed clearly the importance of the balance between inter- and intra-molecular interaction allowing the expression of chirality at mesoscopic level. ${ }^{23}$
In the present paper, we investigated the self-assembled structures of dicationic gemini surfactant $\mathrm{C}_{\mathrm{s}} \mathrm{H}_{2 \mathrm{~s}}-\alpha, \omega-\left(\mathrm{Me}_{2} \mathrm{~N}^{+} \mathrm{C}_{n} \mathrm{H}_{2 n+1}\right)_{2}$ denominated as $\mathrm{n}-\mathrm{s}-\mathrm{n}$ hereafter mixed with GMP-Na $\mathrm{N}_{2}$, n-s-n $\mathrm{X}_{2}+\mathrm{GMP}-\mathrm{Na}_{2}$ where $\mathrm{X}$ represents counterions of $n-s-n$. We focused on how various parameters affect the interaction between gemini surfactants and mixture of the counterions which can be chiral or non-chiral, leading to or disrupting the hierarchical chirality expression. Investigated physico-chemical parameters include $\mathrm{pH}$, aging time, temperature, nature of the competing counterions, GMP/gemini ratio and structure of gemini amphiphile backbone. We will discuss the hierarchical structure of micrometric helical aggregates and propose a mechanism of their formation along with the dynamics of ion exchange.

\section{Materials and Methods}

Guanosine 5'-monophosphate disodium salt was purchased from Acros Organics. All other chemicals were purchased from Sigma Aldrich and used without further purification. All the samples were prepared in ultrapure water $(18.2 \mathrm{M} \Omega \mathrm{cm})$ from Purelab ultra ELGA system.

Synthesis of gemini bromides

Bis(quaternary ammonium) surfactants having the structure $\mathrm{C}_{s} \mathrm{H}_{2 \mathrm{~s}}-\alpha, \omega-\left(\mathrm{Me}_{2} \mathrm{~N}^{+} \mathrm{C}_{n} \mathrm{H}_{2 n+1} \mathrm{Br}^{-}\right)_{2}$ referred as n-s-n $\mathrm{Br}_{2}$ (Scheme 1a) were synthesized as previously reported. ${ }^{24}$ Gemini amphiphiles with chain lengths of $n=10,12,14$ and 16 carbons as well as

1 CBMN, UMR 5248, CNRS-Université de Bordeaux-IPB 2 rue Robert Escarpit, 33607, Pessac, France

2 Laboratoire du Futur, UMR 5258, CNRS-Université de Bordeaux-Solvay 178 avenue du Dr Schweitzer, 33608, Pessac, France

3 School of Energy Science, Kyoto University, Yoshida-Honmachi, Sakyo-ku, 606-8501, Kyoto, Japan

4 ISM, UMR 5255, CNRS-Université de Bordeaux, 351 Cours de la Libération, 33405, Talence, France

Received: ((will be filled in by the editorial staff)) Revised: ((will be filled in by the editorial staff)) Published online: ((will be filled in by the editorial staff)) 
spacer of 2, 4 and 6 carbons were synthesized following the same synthetic route.

(a)

$$
\begin{array}{lll}
{ }_{\ominus}^{\mathrm{X}} & \mathrm{n}=10,12,14,16 \\
\mathrm{~s}=2,4,6
\end{array}
$$

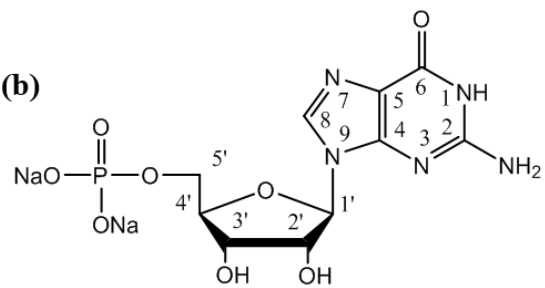

Scheme 1. (a) Chemical structures of cationic gemini amphiphile used in the study and (b) guanosine-5'monophosphate disodium salt (GMP-Na $)_{2}$.

Synthesis of gemini surfactants with the guanosine-5'monophosphate (GMP) as counter-anion, n-s-nGMP 2

The acid form of guanosine-5'- monophosphate was obtained from the corresponding disodium salt on an ion exchange column. $200 \mathrm{~mL}$ of $2 \mathrm{M} \mathrm{HCl}$ were passed through the cationic ion-exchange column filled with $60 \mathrm{~g}$ of DOWEX resin. Then the acid was washed out from the column with ultra pure MilliQ $\mathrm{H}_{2} \mathrm{O}$ until neutral pH. $250 \mathrm{mg}$ of guanosine-5'- monophosphate disodium salt in $5 \mathrm{~mL}$ of $\mathrm{H}_{2} \mathrm{O}$ were passed through the column. The solution was collected in a $1 \mathrm{~L}$ flask until neutral $\mathrm{pH}$. The solution of GMP was concentrated down to $\sim 30 \mathrm{~mL}$ and finally freeze-dried. Column was recuperated by $50 \mathrm{~mL}$ of $2 \mathrm{M} \mathrm{NaOH}$ and then washed with $\mathrm{H}_{2} \mathrm{O}$ until neutral $\mathrm{pH}$.

Gemini amphiphiles with the acetate anion n-s-nAc2 were synthesized as previously reported. ${ }^{24}$

Gemini amphiphiles with GMP counterion were synthesized by slow addition of $n-s-n \mathrm{Ac}_{2}$ (methanol solution) to 2.2 eq. of GMP (aqueous solution) under stirring. White precipitate of $n-s-n G M P_{2}$ was filtered out, washed with acetone and freeze dried from aqueous solution.

Proton NMR spectra were used to check the absence of the peak of acetate $(6 \mathrm{H}$ at $1.90 \mathrm{ppm})$ and the $2: 1$ stoichiometry of GMP to gemini.

Typical example of 12-2-12GMP ${ }^{1} \mathrm{H}$ NMR $\left(300 \mathrm{MHz}, \mathrm{D}_{2} \mathrm{O}, 25^{\circ} \mathrm{C}\right.$, $\delta$ ppm, TMS): 8.08 (s, 2H), $5.91(\mathrm{~d}, J=6.1 \mathrm{~Hz}, 2 \mathrm{H}), 4.76(\mathrm{~d}, \mathrm{~J}=$ $0.7 \mathrm{~Hz}, 2 \mathrm{H}), 4.49-4.39(\mathrm{~m}, 2 \mathrm{H}), 4.07(\mathrm{dd}, J=5.1,3.3 \mathrm{~Hz}, 2 \mathrm{H})$, $3.87(\mathrm{~s}, 2 \mathrm{H}), 3.45-3.33(\mathrm{~m}, 2 \mathrm{H}), 3.18(\mathrm{~s}, 4 \mathrm{H}), 1.76(\mathrm{~s}, 2 \mathrm{H}), 1.34$ $(\mathrm{s}, 4 \mathrm{H}), 1.25(\mathrm{~s}, 14 \mathrm{H}), 0.88-0.77(\mathrm{~m}, 2 \mathrm{H})$.

\section{Sample preparation}

In this paper, we compare the self-assembly of the n-s-nGMP 2 formed in solution (synthesis described in the previous paragraph) and the mixture of $n-s-n X_{2}$ (X being $\mathrm{Ac}, \mathrm{Br}, \mathrm{Cl}$, I or $\mathrm{NO}_{3}$ ) with GMP-Na $\mathrm{N}_{2}$ which allow an equilibrium between the $X$ and the GMP $^{-}$at the surface of the gemini assembly. For this second study, the samples are prepared as described below:

First, $\mathrm{n}-\mathrm{s}-\mathrm{nX} \mathrm{X}_{2}$ was dissolved in water by heating to $70^{\circ} \mathrm{C}$ to get a $20 \mathrm{mM}$ solution. Then $500 \mu \mathrm{L}$ of this solution were mixed with $500 \mu \mathrm{L}$ of a $40 \mathrm{mM}$ Guanosine 5'-monophosphate disodium salt aqueous solution (GMP-Na ${ }_{2}$ ). White precipitate was formed upon components mixing. Next, $\mathrm{pH}$ was adjusted to desired value with a $1 \mathrm{M}$ acetic acid. Finally, samples were heated at $70{ }^{\circ} \mathrm{C}$ for 5 minutes and stored at $20{ }^{\circ} \mathrm{C}$ for aging. To prepare $20 \mathrm{mM}$ solution of $12-2-12 \mathrm{I}_{2}\left(\mathrm{~T}_{\mathrm{k}}=58^{\circ} \mathrm{C}\right)$ it has been dissolved at $100{ }^{\circ} \mathrm{C}$ in boiling water prior to the mixing with guanosine 5'-monophosphate disodium salt.

Synthesis of the silica replica

For the silica transcription of organic micrometric helices, sodium metasilicate aqueous solution was acidified with acetic acid down to $\mathrm{pH}$ 5.9-6. Acidity was chosen to be identical to that of the organic template since its morphology is $\mathrm{pH}$ sensitive as we will show in the discussion. $100 \mu \mathrm{L}$ of precursor were added in one shot to $100 \mu \mathrm{L}$ of organic helices without any stirring or sonication, and the mixture was stored at $20^{\circ} \mathrm{C}$ for the silica condensation. $\mathrm{Na}_{2} \mathrm{SiO}_{3} /$ acetic acid ratio $=1: 2, \quad \mathrm{Na}_{2} \mathrm{SiO}_{3}$ concentration of $200 \mathrm{mM}$ and reaction time of 1 hour were found to be optimal parameters for the formation of the silica replica. After the end of transcription, samples were washed with water and $\mathrm{HBr}(100 \mathrm{mM}, 1: 1 \mathrm{v} / \mathrm{v})$ was added for the template dissolution. Excess of $\mathrm{Br}^{-}$ions favors GMP exchange towards the bromide in the surfactant structure. Two water soluble compounds are formed: GMP and $n-s-\mathrm{nBr}_{2}$. They can be removed then by washing the water.

\section{NMR}

After one week of aging, samples were centrifuged and the precipitates were dissolved in $500 \mu \mathrm{L}$ of $\mathrm{DMSO}-\mathrm{d}_{6}$ in the presence of $2 \mu \mathrm{L}$ of $48 \% \mathrm{HBr}$ in standard $5 \mathrm{~mm}$ glass NMR tube. ${ }^{1} \mathrm{H}$ NMR spectra were recorded on Bruker Avance $300 \mathrm{MHz}$ NMR spectrometer. The integration of NMR spectra was calibrated by the amphiphile part of compound. We used the integration of protons $\mathrm{H} 8, \mathrm{H} 1$ ' and $\mathrm{H} 4{ }^{\prime}$ ( $\mathrm{L}, \mathrm{K}$ and $\mathrm{H}$ on Figure $\mathrm{S} 1$ in $\mathrm{SI}$ ) of guanosine-5'-monophosphate for the quantification of amount of GMP present in the aggregates.

Optical Microscopy with Differential Interferential Contrast (DIC).

Samples sealed between slide glass and cover glass were observed with a NIKON Eclipse PhysioStation E600FN with adequate condensers and prism for DIC observations.

\section{Electron microscopy}

The organic samples have high enough electron density for the visualization in Transmission Electron Microscope (TEM) without additional staining. TEM observations were performed using a Philips EM 120 electron microscope operating at $120 \mathrm{kV}$ and the images were collected by $2 \mathrm{k} \times 2 \mathrm{k}$ Gatan ssCCD camera. Scanning Electron Microscopy (SEM) observations were performed on SEM-FEG JEOL $6700 \mathrm{~F}$ microscope operating at 5 $\mathrm{kV}$ after AuPd20 metalization.

\section{Results}

We first investigated the stoichiometric 1:2 complex of 12-2-12 and GMP, synthesized by ion exchange. When solubilized at $70^{\circ} \mathrm{C}$ and cooled down to $20^{\circ} \mathrm{C}$, at the early stage, spherical structures $(\sim 1 \mu \mathrm{m})$ are observed, which evolve to achiral needle-like fibers of around $500 \mathrm{~nm}$ to $1 \mu \mathrm{m}$ width after two days which did not evolve afterwards. The TEM images show that these micrometric structures are assembled from smaller nanometric fibers of around 10-20 nm diameter (Figure S2). We then investigated the effect of the presence of other anions, by mixing $12-2-12 X_{2}$ and GMP-Na. The effect of various parameters listed in Table 1 is studied as described in the following. 
Table 1. List of experimental parameters

\begin{tabular}{|c|c|c|c|c|}
\hline $\begin{array}{l}\text { Studied } \\
\text { parameter }\end{array}$ & $\begin{array}{l}\text { Gemini } \\
\text { structure }\end{array}$ & $\begin{array}{l}\text { GMP/gemini } \\
\text { ratio }\end{array}$ & $\mathrm{pH}$ & $\mathrm{T},{ }^{\circ} \mathrm{C}$ \\
\hline $\mathrm{pH}$ & $12-2-12 \mathrm{Br}_{2}$ & $2: 1$ & $\begin{array}{l}7.4,6.4, \\
5.9,4.1\end{array}$ & 20 \\
\hline Temperature & $12-2-12 \mathrm{Br}_{2}$ & $2: 1$ & 5.9 & $\begin{array}{l}4,20 \\
30\end{array}$ \\
\hline $\begin{array}{l}\text { GMP/gemini } \\
\text { ratio }\end{array}$ & $12-2-12 \mathrm{Br}_{2}$ & $0.4: 1-4: 1$ & 5.9 & 20 \\
\hline $\begin{array}{l}\text { Counter-ion } \\
\text { nature }\end{array}$ & $\begin{array}{l}12-2-12 \mathrm{X}_{2} \\
\mathrm{X}=\mathrm{Ac}, \mathrm{Br}, \\
\mathrm{Cl}, \mathrm{I}, \mathrm{NO}_{3}\end{array}$ & $0.4: 1-4: 1$ & 5.9 & 20 \\
\hline $\begin{array}{l}\text { Gemini } \\
\text { structure }\end{array}$ & $\begin{array}{l}\mathrm{n}-\mathrm{s}-\mathrm{nBr}_{2} \\
\mathrm{n}=10,12 \\
14,16 \\
\mathrm{~s}=2,4,6\end{array}$ & $2: 1$ & 5.9 & 20 \\
\hline
\end{tabular}

GMP- $\mathrm{Na}_{2}$ was added to gemini amphiphile to obtained desired GMP/gemini ratio at final gemini concentration of $10 \mathrm{mM}$. The $\mathrm{pH}$ is adjusted with $1 \mathrm{M}$ acetic acid. Sample is dissolved at $70^{\circ} \mathrm{C}$ and aged at given temperature $T$.

\section{Effect of the $\mathrm{pH}$ and temperature}

We first investigated the effect of $\mathrm{pH}$ on the self-assembly of 12 $2-12 \mathrm{Br}_{2}+\mathrm{GMP}-\mathrm{Na}_{2}$ mixture. The protonation of GMP varies at $\mathrm{pH}=0.7,2.4,6.1$ and 9.4 (Figure S3). The GMP/12-2-12 ratio and the concentration of $12-2-12 \mathrm{Br}_{2}$ was fixed to be $2: 1$ and 10 $\mathrm{mM}$, respectively, and the $\mathrm{pH}$ was controlled by addition of $1 \mathrm{M}$ acetic acid. When no acetic acid is added $(\mathrm{pH}=7.4)$ the 12-2$12 \mathrm{Br}_{2} / \mathrm{GMP}-\mathrm{Na}_{2}$ mixture was not completely soluble even at $70{ }^{\circ} \mathrm{C}$ and formed poorly structured precipitates upon cooling and did not evolve with time (Figure 1-a). At $\mathrm{pH}=6.4$, the mixture became soluble upon heating to $70^{\circ} \mathrm{C}$ and formed poorly structured precipitates when cooled (Figure 1-b). At pH $=5.9$ on the other hand, the formation of helical fibers was observed after 1 hour (Figure 1-c). A further decrease in $\mathrm{pH}$ to 4.1 leads to the elongation of the helices and their aggregation (Figure 1-d). Compared to the protonation of GMP as a function of $\mathrm{pH}$ as shown in Figure S3, this indicates that helix formation is only observed in the range of $\mathrm{pH}$ for which GMP is monoanionic.

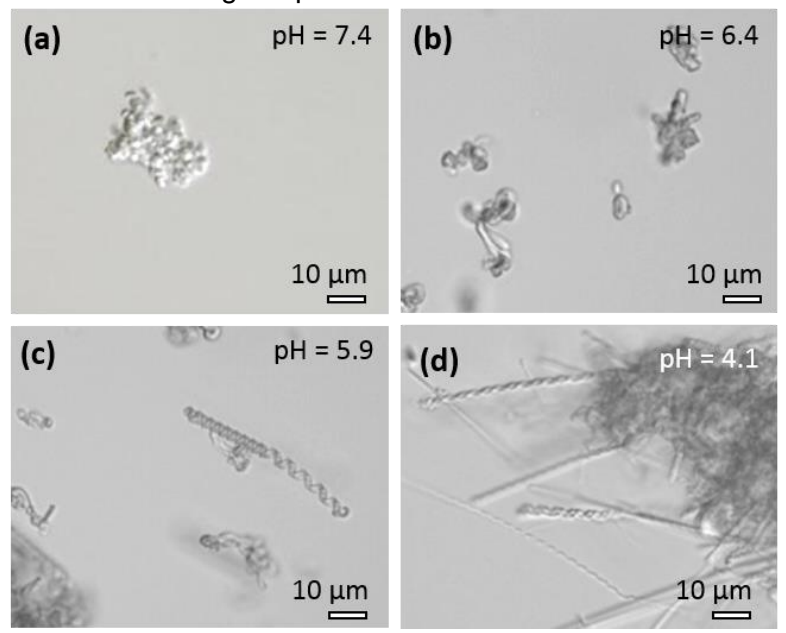

Figure 1. Optical microscope images of the $12-2-12 \mathrm{Br}_{2}+\mathrm{GMP}$ $\mathrm{Na}_{2}$ (1:2) mixture at various $\mathrm{pH}$ (adjusted by acetic acid) after 24 hours: (a) $\mathrm{pH}=7.4$, (b) $\mathrm{pH}=6.4$, (c) $\mathrm{pH}=5.9$, (d) $\mathrm{pH}=4.1$.

To further investigate the effect of temperature on the selfassembly, the ratio of $\mathrm{GMP} /$ gemini was $2: 1$, the $12-2-12 \mathrm{Br}_{2}$ concentration was $10 \mathrm{mM}$ and the $\mathrm{pH}$ was 5.9. After the complete dissolution of the mixture in water by heating to $70^{\circ} \mathrm{C}$, the solution was cooled down and aged at $1{ }^{\circ} \mathrm{C}, 20^{\circ} \mathrm{C}$ and $30^{\circ} \mathrm{C}$ In the sample aged at $1^{\circ} \mathrm{C}$, the kinetics of the helix formation was very slow and only a small number of helical ribbons was observed after one week (Figure 2-b). The samples aged both at $20{ }^{\circ} \mathrm{C}$ and at $30^{\circ} \mathrm{C}$ exhibit much faster kinetics: helices were formed already after 1 hour. While helical structures formed at $20{ }^{\circ} \mathrm{C}$ were well separate (Figure 2-c) and became longer and larger in diameter upon aging (Figure $2-\mathrm{d}$ ), at $30^{\circ} \mathrm{C}$ they tend to aggregate (Figure 2-e) and their diameters also increased with time (Figure 2-f). Based on these observations, we selected $\mathrm{pH}$ 5.9 and aging temperature $20^{\circ} \mathrm{C}$ for further studies.
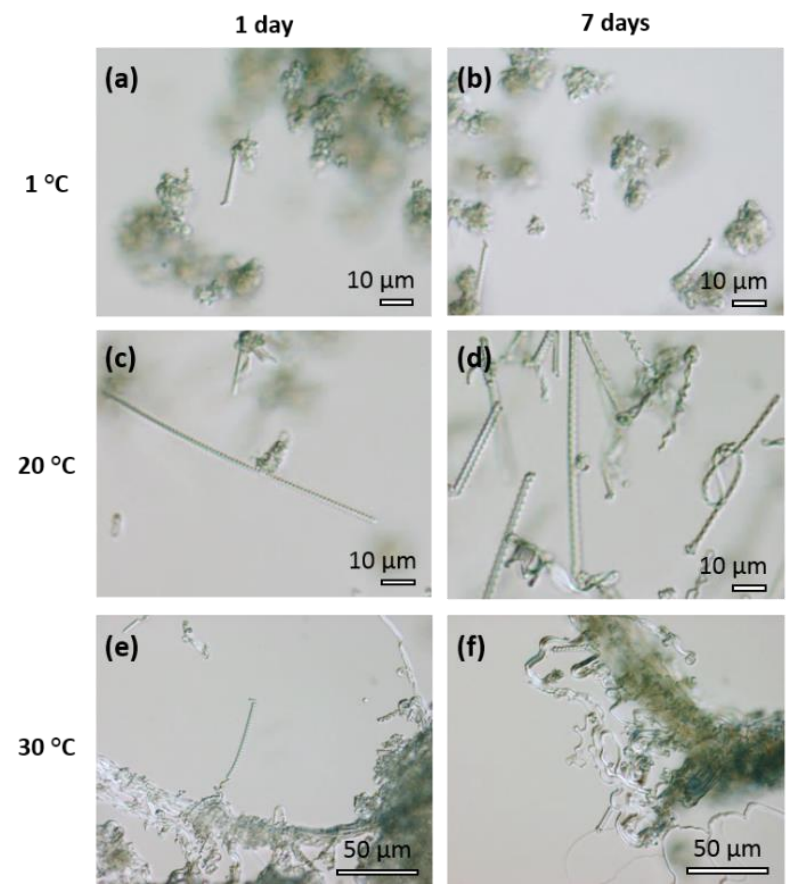

Figure 2. Optical microscope images of the $12-2-12 \mathrm{Br}_{2}+\mathrm{GMP}-$ $\mathrm{Na}_{2}(1: 2)$ mixture $(\mathrm{pH}=5.9)$ aged at various temperatures: (a and b) $\mathrm{T}=1{ }^{\circ} \mathrm{C}$, (c and d) $\mathrm{T}=20^{\circ} \mathrm{C}$, (e and f) $\mathrm{T}=30^{\circ} \mathrm{C}$. Aging time is $(\mathrm{a}, \mathrm{c}, \mathrm{e}) 1$ day and $(\mathrm{b}, \mathrm{d}, \mathrm{f}) 7$ days, respectively.

The more detailed observation of these helices by TEM revealed that they have double helical structures (Figure 3 a) formed by two strands of around $500 \mathrm{~nm}$ diameter (red and yellow arrows) which coexist with smaller 10-20 nm diameter filaments (sky blue arrow). The sol-gel silicification of these structures allowed to have solid replicas of the morphology. The SEM and TEM observations (Figure $3 \mathrm{~b}, \mathrm{c}$ and e) confirmed the morphology of the organic double helix. The Figure 3-d revealed the hollow structure of the silica replication, the void interior corresponding to the initial organic helix location.

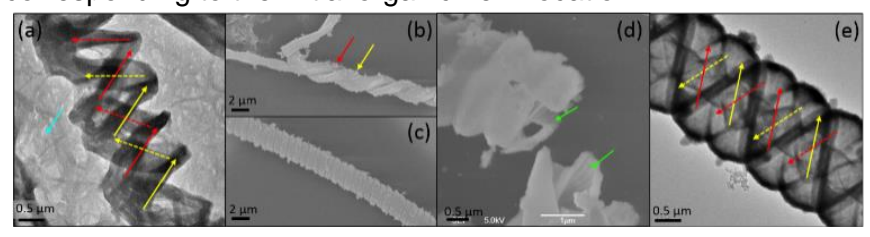

Figure 3. (a) TEM of organic micrometric helices without staining. (b-d) SEM and (e) TEM of silica replica keeping the original structure in suspension without deformation after drying. Composition: $12-2-12 \mathrm{Br}_{2}+\mathrm{GMP}_{-} \mathrm{Na}_{2}$ (1:3.2), $\mathrm{pH}$ is 5.9 , aging time is 7 days, surfactant concentration is $10 \mathrm{mM}$.

\section{Effect of the co-counterion nature}


Previously, we have shown that the self-assembly of gemini surfactant depends strongly on the nature of counterions. ${ }^{20,21,23}$ It was demonstrated that in the presence of Hofmeister anions such as iodide, bromide, nitrate, chloride and acetate, ${ }^{24,27}$ the aggregation properties such as critical micelle concentration (CMC), aggregation number, micellization energy and ionization degree of gemini amphiphiles are strongly modified, clearly following a trend as the free energy of hydration of these anions increases in the order $\mathrm{I}^{-}<\mathrm{NO}_{3}^{-} \sim \mathrm{Br}^{-}<\mathrm{Cl}^{-}<$Acetate. ${ }^{24}$ We therefore evaluated the effect of the nature of the anion $X^{-}$in competition with GMP on the morphology of the aggregates obtained from the mixture $12-2-12 X_{2}+$ GMP-Na2. Here, GMP$\mathrm{Na}_{2}$ solutions were added to the solution of $12-2-12 X_{2}$, so that the final concentration of 12-2-12 was always $10 \mathrm{mM}$. All the solutions had $\mathrm{pH} 5.9$ and were aged at $20^{\circ} \mathrm{C}$ for 7 days. The Figure 4 represents the aggregation morphologies as a function of the GMP/gemini ratio in the mixture and the nature of the coanion.

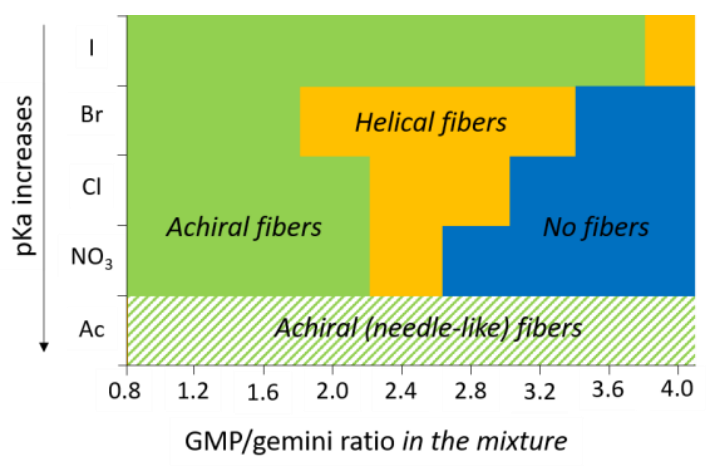

Figure 4. Effect of the co-anion nature on the morphology of self-assembly at various GMP/gemini ratios in the mixture after 7 days aging. Concentration of $12-2-12$ gemini is $10 \mathrm{mM}, \mathrm{pH}=5.9$, aging temperature $20^{\circ} \mathrm{C}$.

When GMP-Na $\mathrm{Na}_{2}$ is mixed with 12-2-12 having bromide counterion $(\mathrm{Br})$, the formation of micrometric helices was observed for the GMP/gemini ratios between 2.0 and 3.2 (Figure S4). Above 3.6 ratio, unstructured precipitates were observed while bellow 1.6, achiral fibers were observed. Interestingly, when 12-2-12 with chloride $(\mathrm{Cl})$ counterions was mixed with GMP- $\mathrm{Na}_{2}$, for the GMP/12-2-12Cl $\mathrm{Cl}_{2}$ ratio up to 2.0, the achiral fibers were observed (Figure S5-d) and no fibers were observed above 3.2. Only at the ratio between 2.4 and 2.8, micrometric helices were observed after 6 hours of aging, which grew in the number and the length with time (Figure S5-e and f). In the case of nitrate, helical structures were formed only at GMP/12-2$12\left(\mathrm{NO}_{3}\right)_{2}$ ratio of 2.4 (Figure S5-h). On the other hand, helical fibers were observed only at much higher ratio for $12-2-12 \mathrm{I}_{2}$, GMP/12-2-12I $I_{2}>4.0$. Finally, when $12-2-12 A c_{2}$ is mixed with GMP-Na2, (Figure S6), only spherical aggregates were observed at first, which transformed to straight fibers regardless of the GMP/12-2-12 ratio.

\section{Effect of the GMP/gemini ratio}

The strong counterions dependence of self-assemblies obtained when $12-2-12 X_{2}$ is mixed with GMP-Na $\mathrm{N}_{2}$ suggests that the 12-212 aggregates are in equilibrium between the ionic species in solution. Here, we focused our study on the partition of GMP between the solution and the aggregates formed by the mixture of $12-2-12 \mathrm{Br}_{2}+\mathrm{GMP}-\mathrm{Na}_{2}$. The concentration of $12-2-12 \mathrm{Br}_{2}$ was $10 \mathrm{mM}$ and the added amounts of GMP-Na $\mathrm{Na}_{2}$ was varied to obtain molecular ratios of GMP to 12-2-12 from 0.4 to 4 . We will refer to this ratio as "in the mixture". After one week of sample aging, we isolated precipitate by centrifugation (self-assembled structures) and analyzed them by proton NMR (see experimental section and Figure S4 for more details regarding the evolution of the morphology vs the GMP- $\mathrm{Na}_{2}$ to $12-2-12 \mathrm{Br}_{2}$ ratio) in order to determine the GMP/gemini ratio in the self-assembled structures, i.e. the amount of GMP complexed with the gemini inside the aggregates, which is in equilibrium with GMP in solution. We will refer to this ratio as in the aggregates.

The Figure 5-a shows GMP/gemini ratio in the aggregates vs GMP/gemini ratio in the mixture.
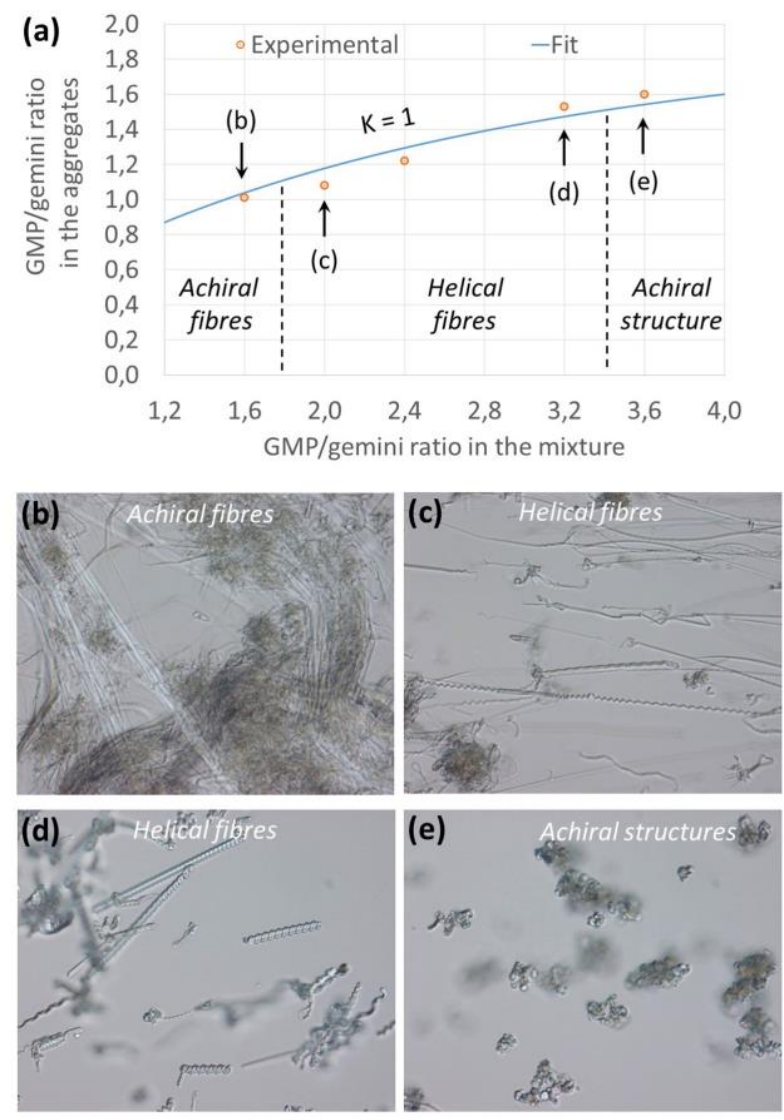

$\underline{10 \mu \mathrm{m}}$

Figure 5. (a) GMP/gemini ratios in the aggregates as a function of corresponding ratios in the starting mixture as determined by NMR measurements. The fit in the plot shows the equilibrium constant $\mathrm{K}=1$ which suggests equal affinity of both $\mathrm{GMP}^{-}$and $\mathrm{Br}^{-}$towards the gemini. (b-e) DIC optical microscopy images corresponding to the conditions indicated by arrows. Experimental conditions: amphiphile concentration is $10 \mathrm{mM}, \mathrm{pH}$ is 5.9 , aging temperature is $20^{\circ} \mathrm{C}$, and aging time is 7 days.

Correlations between GMP/gemini (in the presence of $\mathrm{Br}^{-}$ counterions) ratios and morphological aspects of self-assembly structures are shown on the Figure 5. The sample with the GMP/gemini ratio in the mixture of 0.4 remains transparent after 1 week of aging whereas all other samples precipitate within several minutes after cooling to $20^{\circ} \mathrm{C}$. The samples having the GMP/gemini ratios in the mixture between 0.8 and 1.6 form clusters of small ribbons within 1 hour. These ribbons continue to grow to create a network of fibers without apparent chirality, achiral fibers, even after 1 week of aging (Figure 5-a and b). Only when the GMP/gemini ratio is between 2.0 and 3.2 in the mixture (Figure S4) which corresponds to the ratios 1.1 and 1.6 in the aggregates (Figure 5-c), helices formation was observed. Helical structures start to form already after 1 hour of aging and within 24 hours, mostly helical structures were observed with a 
few tens of microns and $\sim 2-5 \mu \mathrm{m}$ diameter (Figure S4). A further increase in GMP/gemini ratio in the mixture (3.6 and 4.0) leads to a precipitate formation with no obvious structure (Figure 5-e).

\section{Effect of surfactant structure}

Finally, we compared the effect of the molecular structures of gemini surfactants in the presence of bromide co-counterions. Due to their dimeric structure, the length of the hydrophobic tails and the length of spacers can be modified independently. In the Figure 6, we show the optical microscope images of the selfassembly structures of gemini bromides with different alkyl chain lengths $n$ and spacers $s$ in the presence of GMP-Na $\mathrm{Na}_{2}$ after one week of aging. The chain length was varied from 12 to 16 and the spacer length from 2 to 6 . The concentration of amphiphile was $10 \mathrm{mM}$, GMP to gemini ratio was $2: 1$ and $\mathrm{pH}=5.9$ in all the experiments.

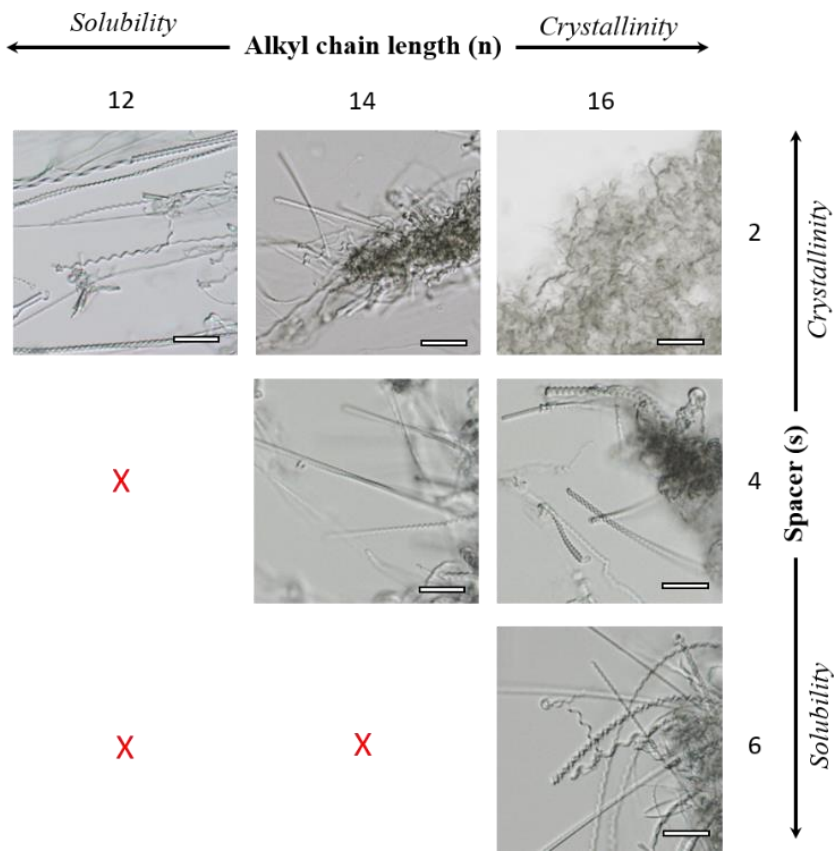

Figure 6. DIC optical microscopy: effect of the surfactant structure on the morphology of self-assembly for the GMP/gemini ratio of 2:1. Aging time is 7 days, $\mathrm{pH}$ is 5.9 , and surfactant concentration is $10 \mathrm{mM}$. Scale bars are $20 \mu \mathrm{m}$. Samples marked with the red crosses were either too soluble (below critical micellar concentration) or not studied due to their extremely high hygroscopy and the resulting difficulties to quantitatively investigate the mixture with GMP Na .

For the gemini with spacer length of 2 carbons, $(n-2-n)$ and the alkyl chain length $C=12$ or 14 , we observed formation of helical structures. When the chain length is further increased to 16 carbons (16-2-16), only wrinkled sheet-like structures were observed. For the spacer length of 4 carbons, clear helices formation was observed with the chain length 14 and 16 carbons (14-4-14 and 16-4-16) already after one hour which became bigger and better defined with time. Increasing the spacer to 6 carbons leads to even more pronounced helical shape of aggregates. The number of helices as well as their length and average diameter increase.

\section{Self-association of the GMP}

The IR spectra of $12-2-12 \mathrm{Br}_{2}+\mathrm{GMP}-\mathrm{Na}_{2}$ (1:2 mixture, $\mathrm{pH}$ 5.9, forming helices) and $12-2-12 \mathrm{Ac}_{2}+\mathrm{GMP}-\mathrm{Na}_{2}$ (1:2 mixture, $\mathrm{pH} 5.9$, forming straight fibers) in $\mathrm{D}_{2} \mathrm{O}(10 \mathrm{mM})$ as well as the GMP- $\mathrm{Na}_{2}$ solution in $\mathrm{D}_{2} \mathrm{O}(10 \mathrm{mM})$ are presented in the Figure 7 in the $3050-2750 \mathrm{~cm}^{-1}$ and $1800-1250 \mathrm{~cm}^{-1}$ regions. The wavenumbers observed for the asymmetric $\left(v_{a} \mathrm{CH}_{2}\right)$ and symmetric $\left(v_{s} \mathrm{CH}_{2}\right)$ stretching vibrations of the $\mathrm{CH}_{2}$ groups of the gemini alkyl chains are similar for the two mixtures (i.e. $2926 \mathrm{~cm}$ ${ }^{1}$ for the $v_{\mathrm{a}} \mathrm{CH}_{2}$ mode and $2854 \mathrm{~cm}^{-1}$ for the $v_{\mathrm{s}} \mathrm{CH}_{2}$ mode). These values are also similar to those published for $\left(\mathrm{C}_{12}\right)_{2} \mathrm{GMP}$ or $\left(\mathrm{C}_{12}\right)_{2} \mathrm{AMP}$ systems, ${ }^{16}$ indicating that the alkyl chains of the nucleoamphiphiles are in the fluid phase with a high rate of gauche conformations. The IR spectrum of the GMP- $-\mathrm{Na}_{2}$ solution in $\mathrm{D}_{2} \mathrm{O}(10 \mathrm{mM})$ in the $1800-1250 \mathrm{~cm}^{-1}$ spectral range is the same as the one published in the literature for unassociated GMP in solution. ${ }^{23}$ The band at $1663 \mathrm{~cm}^{-1}$ is assigned to the carbonyl stretching vibration and the bands in the $1600-1520 \mathrm{~cm}^{-}$ 1 region can be described as collective in-plane purine ring vibrations. The band at $1579 \mathrm{~cm}^{-1}$ comes from the imidazole ring and has a strong contribution of the C-N stretching of the pyrimidine ring whereas the shoulder at $1566 \mathrm{~cm}^{-1}$ is mainly due to the pyrimidine ring with a significant contribution from the C$\mathrm{NH}_{2}$ group. ${ }^{24}$ The IR spectrum of $12-2-12 \mathrm{Br}_{2}+\mathrm{GMP}-\mathrm{Na}_{2}$ mixture in $\mathrm{D}_{2} \mathrm{O}(10 \mathrm{mM})$ shows marked modifications from that of the unassociated GMP. The carbonyl band shifts to higher wavenumbers (ca $1668 \mathrm{~cm}^{-1}$ ) and the maximum of the band profile related to purine ring vibrations changed to $1566 \mathrm{~cm}^{-1}$. Such spectral changes have already been observed for selfassociation of 5'-GMP in aqueous solution. ${ }^{25}$ The shift of the carbonyl band is even more pronounced (ca $1674 \mathrm{~cm}^{-1}$ ) for the $12-2-12 \mathrm{Ac}_{2}+\mathrm{GMP}-\mathrm{Na}_{2}$ mixture in $\mathrm{D}_{2} \mathrm{O}(10 \mathrm{mM})$. Unfortunately, the purine ring vibrations cannot be observed on this system due to the strong absorption of the asymmetric stretching vibration of the carboxylate group $\left(v_{\mathrm{a}} \mathrm{COO}\right)$, expected at $1563 \mathrm{~cm}^{-1} .{ }^{16}$ Nevertheless, the shift of the carbonyl group $\left(1674 \mathrm{~cm}^{-1}\right.$ for 12-2$12 \mathrm{Ac}_{2}+\mathrm{GMP}-\mathrm{Na}_{2}$ vs $1668 \mathrm{~cm}^{-1}$ for $\left.12-2-12 \mathrm{Br}_{2}+\mathrm{GMP}-\mathrm{Na}_{2}\right)$ seems to indicate the higher ordering of guanine residues in the supramolecular structure of the $12-2-12 \mathrm{Ac}_{2}+\mathrm{GMP}-\mathrm{Na}_{2}$ mixture.
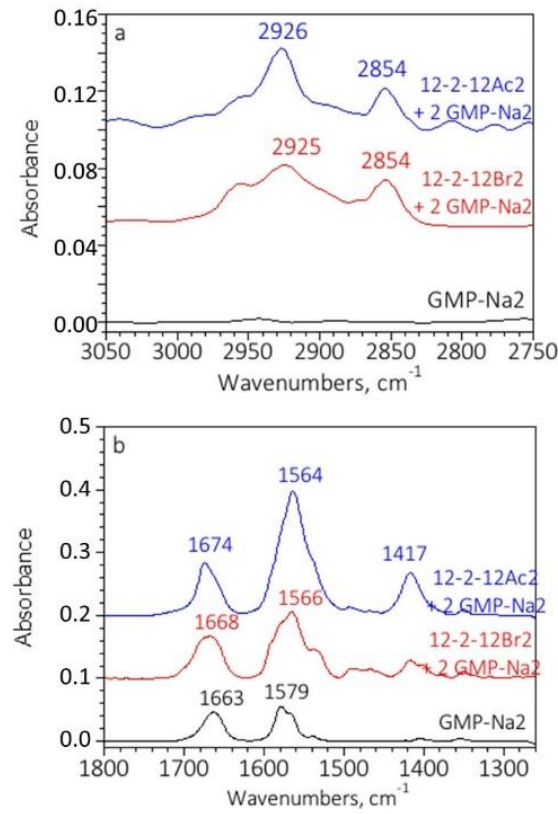

Figure 7. IR spectra of $12-2-12 \mathrm{Br}_{2}+\mathrm{GMP}-\mathrm{Na}_{2}$ and $12-2-12 \mathrm{Ac}_{2}+$ GMP- $\mathrm{Na}_{2}$ mixtures in $\mathrm{D}_{2} \mathrm{O}(10 \mathrm{mM})$ as well as the GMP- $-\mathrm{Na}_{2}$ solution in $\mathrm{D}_{2} \mathrm{O}(10 \mathrm{mM})$ in (a) the $3050-2750 \mathrm{~cm}^{-1}$ and (b) 1800 $1250 \mathrm{~cm}^{-1}$ regions.

\section{Discussion}

We have shown that the complex gemini/GMP in the presence of co-anions can cooperatively express chirality at the micrometric 
scale under a certain condition requiring a very subtle balance between the different physico-chemical parameters. The competition of GMP and co-anion $\mathrm{X}$ at the interface of gemini assemblies is determined by the nature and quantity of co-ions as well as the gemini molecular structures, and it is crucial for determining the molecular assembly kinetics and morphologies. First, it has been observed that the stoichiometric compounds $12-2-12 \mathrm{GMP}_{2}$ only form needle-like achiral fibers. This result is in contrast with our previous reports ${ }^{20,21}$ which showed that with one-head-two-tails monocationic surfactant, dialkyldimethylammonium, 1:1 stoichiometric complex with GMP or AMP (adenosine monophosphate) showed the formation of micrometric helices. With gemini-type dicationic surfactant, only in the presence of non-chiral co-anions which have strong interaction with ammonium headgroup of gemini such as Bromide, the formation of micrometric helices was observed with GMP. It is noteworthy that with co-anions with weaker interaction such as acetate, no helices were observed. The quantification of GMP with respect to gemini and $\mathrm{Br}^{-}$in the chiral nanoaggregates by NMR showed that at the equilibrium, GMP/gemini ratio in the aggregates is lower than the ratio in the bulk and the helices formation was observed when the GMP/gemini ratio is between 2.0 and 3.2 in the mixture which corresponds to the ratios 1.1 and 1.6 in the aggregates, respectively. This means that at the ratios in the mixture of 2.0, the stoichiometric mixture of dicationic 12-2-12 and monoanionic GMP, only 55\% of GMP are complexed with gemini (1.1/2 as calculated from Figure 5-a) and $45 \%$ of cations from gemini are complexed with bromide anions (GMP and Bromide are in competition at the aggregates interface). Inversely $45 \%$ of GMP and $55 \%$ of bromide remain in solution.

The FT-IR spectra of the helix forming $12-2-12 \mathrm{Br}_{2}+\mathrm{GMP}-$ $\mathrm{Na}_{2}$ and the fiber forming $12-2-12 \mathrm{Ac}_{2}+\mathrm{GMP}-\mathrm{Na}_{2}$ mixture in $\mathrm{D}_{2} \mathrm{O}$ $(10 \mathrm{mM})$ demonstrated that in both cases, the alkyl chains of the nucleoamphiphiles are in the fluid phase with a high rate of gauche conformations, similar to the spectra obtained from gemini in micellar solution. Meanwhile, the IR bands associated to the GMP shows marked modifications from that of the GMP in solution. The carbonyl band shifts to higher wavenumbers, 1663 to $1668 \mathrm{~cm}^{-1}$ (along with the shift in purine ring vibrations to 1566 $\mathrm{cm}^{-1}$ ) for $\mathrm{Br}$ system and 1663 to $1674 \mathrm{~cm}^{-1}$ for acetate system. These results demonstrate the different level of ordering of guanine residues at the aggregates interface with a higher level of organization of GMP in the supramolecular structure of the 12$2-12 \mathrm{Ac}_{2}+\mathrm{GMP}-\mathrm{Na}_{2}$ mixture than that of the $12-2-12 \mathrm{Br}_{2}+\mathrm{GMP}-$ $\mathrm{Na}_{2}$. This indicates that a certain degree of intermolecular interaction between GMP at the aggregates interface is necessary for the chirality expression of the assemblies, but too strong interactions between the GMPs prohibit it. The fact that the micrometric helices are only observed in a given range of $\mathrm{GMP} / \mathrm{Br}$ ratios indicates that it is indeed the competition between $\mathrm{Br}$ and GMP in interaction with gemini aggregates determines the interfacial concentration of GMP, which needs to be high enough to induce chirality to the surfactant moieties, but should not be too high to give the flexibility to the assemblies (Figure 8).

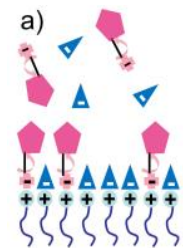

b)
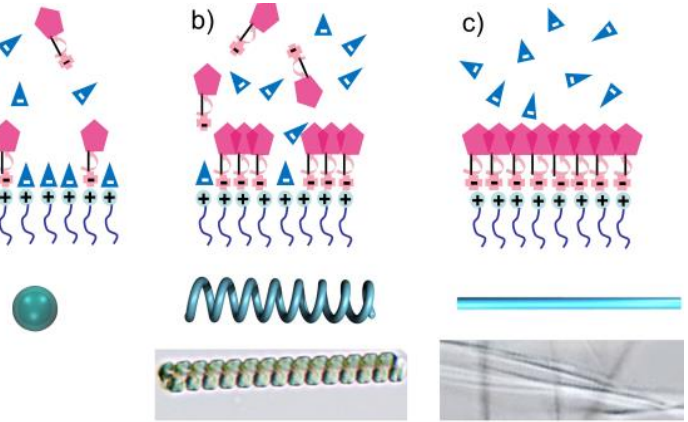

Figure 8. Schematic presentation of GMP (pink) and Br- (blue triangle) interacting at the surface of gemini assemblies. The competition between $\mathrm{Br}$ and GMP in interaction with gemini aggregates determines the interfacial concentration of GMP which needs to be in a given range so that micrometric helices are observed (b) When it is too low, no induction of chirality to the surfactant moieties is observed (a), but should not be too high (c) to give the flexibility to the assemblies so that they can express mesoscopic chirality.

It is interesting to compare these results with our previous report with gemini surfactants with polyalanine counterions ${ }^{23}$ for which cooperative reinforcement of gemini surfactants and polyalanine counterions were observed. Helix formation was observed either with strong inter-peptide interaction with weakly ordered gemini or weakly interacting peptides with strongly ordered gemini. In the present system, gemini remain disordered and the interaction between GMP was controlled by the proportion of non-chiral counterions to GMP at the interface, the presence of the former is crucial for disrupting the too strong intermolecular association between GMP prohibiting the helix formation.

The molecular organization and the resulting supramolecular structures are not only affected by the proportion of GMP and non-chiral counterions. The alkyl chain length as well as the spacer length of gemini also affect the helix formation. The longer the alkyl chains and the shorter the spacer length, the more crystalline the assemblies are as it has been previously demonstrated whereas shorter alkyl chain and longer spacer tend to increase their solubility (higher $\mathrm{cmc}$ ) ${ }^{26}$ For the present system, helical assemblies are observed either for long hydrocarbon chain with long spacer length, or short hydrocarbon chain with short spacer length, which is in good agreement with our observation that a subtle balance of hydrophilicity and hydrophobicity of the gemini with respect to the counterions are crucial for the helix formation. ${ }^{23}$

The effect of the nature of co-anions on the helix formation is very complex. On the first view, the relative affinity of co-ions and GMP with gemini has crucial roles which can be observed by the parameters such as the Krafft temperature of $12-2-12 X_{2}$ (Figure 4). For example, higher Krafft temperature of $12-2-12 \mathrm{I}_{2}$ $\left(T_{k} \approx 58{ }^{\circ} \mathrm{C}\right.$ ) with respect to $T_{k} \approx 48{ }^{\circ} \mathrm{C}$ for $12-2-12 \mathrm{GMP}_{2}$ and $\mathrm{T}_{\mathrm{k}} \approx$ $20{ }^{\circ} \mathrm{C}$ for $12-2-12 \mathrm{Br}_{2}$ favors the formation of $12-2-12 \mathrm{I}_{2}$ with respect to the formation of $12-2-12 \mathrm{GMP}_{2}$. Therefore, only at high GMP concentration, (GMP/gemini ratio of 4.0) the GMP interfacial concentration is high enough to allow helices formation. However, the affinity of co-ions vs GMP with gemini alone does not explain the tendency of helix formation. Whilst the boundary from helices to no fibers as a function of GMP/coions ratio is observed following the trend, Chloride $<$ Bromide $<$ lodide, which can be explained by the affinity between co-ions and 12-2-12, the tendency for the boundary at lower GMP/coions ratio, from non-chiral fibers to helices does not follow this 
trend. With bromide as counterion, we obtained the widest range of the GMP/gemini ratios at which helices form. With chloride having weaker affinity with gemini $\left(T_{k} \approx 10{ }^{\circ} \mathrm{C}\right)$ or with iodide having stronger affinity, this range is smaller. Also, for Nitrate which has similar affinity with gemini as Bromide (similar $T_{k} \approx$ $22{ }^{\circ} \mathrm{C}$ ) the range of the $\mathrm{GMP} /$ gemini ratios for the helices formation was very small formed.

Indeed, as we have previously shown, ${ }^{24,27}$ the effect of the anionic counterions on the self-assembling properties of amphiphilic molecules is determined by the ensemble of parameters including the hydration free energy of the co-ions and inter-molecular (surfactant-counterion, counterioncounterion) interaction (electrostatic, $\pi$ interaction, hydrogen bond). For the work presented in this paper, the expression of the supramolecular chirality of gemini-GMP-co-ion systems clearly results from the complex balance between interfacial concentration of GMP-co-ion and their organization.

\section{Conclusion}

The self-assemblies of nucleoamphiphiles, dicationic "gemini" surfactant /guanosine-5'-monophosphate in the presence of nonchiral counterions were investigated. Only in a defined range of various parameters, the chirality of GMP is expressed at mesoscopic level and micrometric double helical structures with $\sim 500 \mathrm{~nm}$ wide ribbons were observed. The subtle equilibrium of chiral GMP and achiral anions population at the interface of the assemblies with water is crucial for the formation of chiral mesostructures which was tunable by the protonation state of GMP through modification of $\mathrm{pH}$, the proportion of $\mathrm{GMP} / \mathrm{X}$ at the aggregates interface and the nature of the co-ion X. Finally, molecular organization/packing can also be controlled by the gemini structure by both tuning the alkyl chain length and the spacer length. This study clearly demonstrates the complex ensemble of the parameters such as the nature of the interface and the molecular packing on the formation of hierarchical micrometrical chiral assemblies.

\section{Acknowledgements}

This work was supported by the Agence Nationale de la Recherche ANR-10-BLAN-0813-12. The authors are grateful to the TEM IECB platform (Marion Decossas and Sisareuth Tan), NMR IECB platform (Axelle Grelard) and Placamat platform for the SEM.

\section{Supporting information :}

Additional supporting information may be found in the online version of this article at the publisher's website.

\section{REFERENCES AND NOTES}

1. Tachibana $\mathrm{T}, \mathrm{Kambara} \mathrm{H}$. Enantiomorphism in the Helical Aggregate of Lithium 12-Hydroxystearate. J Am Chem Soc 1965; 87:3015-3016.

2. Hotten B, Birdsall D. Fine Structure and Rheological Properties of Lithium Soap-Oil Dispersions. J Colloid Sci 1952;7: 284-294.

3. Yashima E, Ousaka N, Taura D, Shimomura K, Ikai T, Maeda K. Supramolecular Helical Systems: Helical Assemblies of Small Molecules, Foldamers, and Polymers with Chiral
Amplification and Their Functions. Chem Rev 2016;116:1375213990.

4. Barclay TG, Constantopoulos K, Matisons J. Nanotubes Self-Assembled from Amphiphilic Molecules via Helical Intermediates. Chem Rev 2014;114:10217-10291.

5. Shimizu T, Masuda M, Minamikawa H. Supramolecular Nanotube Architectures Based on Amphiphilic Molecules. Chem Rev 2005;105:1401-1444.

6. Amabilino DB. Chirality at the Nanoscale. Wiley-VCH; 2009. $380 \mathrm{p}$.

7. Hatip Koc M, Cinar Ciftci G, Baday S, Castelletto V, Hamley IW, Guler MO. Hierarchical Self-Assembly of HistidineFunctionalized Peptide Amphiphiles into Supramolecular Chiral Nanostructures. Langmuir 2017;33:7947-7956.

8. Hamley IW, Dehsorkhi A, Castelletto V, Furzeland S, Atkins D, Seitsonen J, Ruokolainen J. Reversible Helical Unwinding Transition of a Self-Assembling Peptide Amphiphile. Soft Matter 2013;9:9290-9293.

9. Iwaura R, Ohnishi-Kameyama M. Construction of Supramolecular Helical Nanofibers Using Renewable Biomaterials: Self-Assembly of a Cytidylic Acid-Appended Bolaamphiphile in Lemon Juice. Chem Commun 2012;48:66336635.

10. Zhou P, Shi R, Yao J, Sheng C, Li H. Supramolecular SelfAssembly of Nucleotide-metal Coordination Complexes: From Simple Molecules to Nanomaterials. Coord Chem Rev 2015;292:107-143.

11. Fameau AL, Houinsou-Houssou B, Novales B, Navailles L, Nallet F, Douliez JP. 12-Hydroxystearic Acid Lipid Tubes under Various Experimental Conditions. J Colloid Interface Sci 2010; 341:38-47.

12. Chiang $\mathrm{Y}-\mathrm{W}, \mathrm{Ho}$ R-M, Burger C, Hasegawa H. Helical Assemblies from Chiral Block Copolymers. Soft Matter 2011;7: 9797-9803.

13. Liang W, He X, Reddy NR, Bai Y, An L, Fang J. Morphology Transformation of Supramolecular Structures in Aqueous Mixtures of Two Oppositely Charged Amphiphiles. Langmuir 2019;35:9004-9010.

14. Yuan T, Sun Z, Mu AU, Zeng M, Kalin AJ, Cheng Z, Olson MA, Fang L. Assembly and Chiral Memory Effects of Dynamic Macroscopic Supramolecular Helices. Chem - A Eur J 2018;24: 16553-16557.

15. Kageyama $\mathrm{Y}$, Ikegami $\mathrm{T}$, Hiramatsu $\mathrm{N}$, Takeda $\mathrm{S}$, Sugawara T. Structure and Growth Behavior of CentimeterSized Helical Oleate Assemblies Formed with Assistance of Medium-Length Carboxylic Acids. Soft Matter 2015;11:35503558.

16. Wang Y, Qi W, Huang R, Yang X, Wang M, Su R, He Z. Rational Design of Chiral Nanostructures from Self-Assembly of a Ferrocene-Modified Dipeptide. J Am Chem Soc 2015;137:7869-7880.

17. Nakashima N, Asakuma S, Kunitake T. Optical Microscopic Study of Helical Superstructures of Chiral Bilayer Membranes. J Am Chem Soc 1985;107:509-510.

18. Smith B, Zastavker YV, Benedek GB. Tension-Induced Straightening Transition of Self-Assembled Helical Ribbons. Phys Rev Lett 2001;87:278101. 
19. Lee HY, Oh H, Lee JH, Raghavan SR. Shedding Light on Helical Microtubules: Real-Time Observations of Microtubule Self-Assembly by Light Microscopy. J Am Chem Soc 2012;134: 14375-14381.

20. Aimé C, Manet S, Satoh T, Ihara H, Park KY, Godde F, Oda R. Self-Assembly of Nucleoamphiphiles: Investigating Nucleosides Effect and the Mechanism of Micrometric Helix Formation. Langmuir 2007;23:12875-12885.

21. Aimé C, Tamoto R, Satoh T, Grelard A, Dufourc EJ, Buffeteau $T$, Ihara $H$, Oda $R$. Nucleotide-Promoted Morphogenesis in Amphiphile Assemblies: Kinetic Control of Micrometric Helix Formation. Langmuir 2009;25:8489-8496.

22. Wang $\mathrm{Y}$, Desbat B, Manet $\mathrm{S}$, Aimé $\mathrm{C}$, Labrot $\mathrm{T}$, Oda R. Aggregation Behaviors of Gemini Nucleotide at the Air-Water Interface and in Solutions Induced by Adenine-Uracil Interaction. J Colloid Interface Sci 2005;283:555-564.

23. Kiagus-Armad R, Brizard A, Tang C, Blatchly R, Desbat B, Oda R. Cooperative and Reciprocal Chiral Structure Formation of an Alanine-Based Peptide Confined at the Surface of Cationic Surfactant Membranes. Chem - A Eur J 2011;17:9999-10009.

24. Manet S, Karpichev Y, Bassani D, Kiagus-Ahmad R, Oda R. Counteranion Effect on Micellization of Cationic Gemini Surfactants 14-2-14: Hofmeister and Other Counterions. Langmuir 2010;26:10645-10656.

25. Hofmeister F. Zur Lehre von Der Wirkung Der Salze. Arch für Exp Pathol und Pharmakologie 1888;24:247-260.

26. Zana R, Xia J. Gemini Surfactants: Synthesis, Interfacial and Solution-Phase Behavior, and Applications. Boca Raton: Taylor \& Francis; 2003. 385 p.

27. Manet S, Karpichev Y, Dedovets D, Oda R. Effect of Hofmeister and Alkylcarboxylate Anionic Counterions on the Krafft Temperature and Melting Temperature of Cationic Gemini Surfactants. Langmuir 2013;29:3518-3526.

\section{Graphical Abstract}

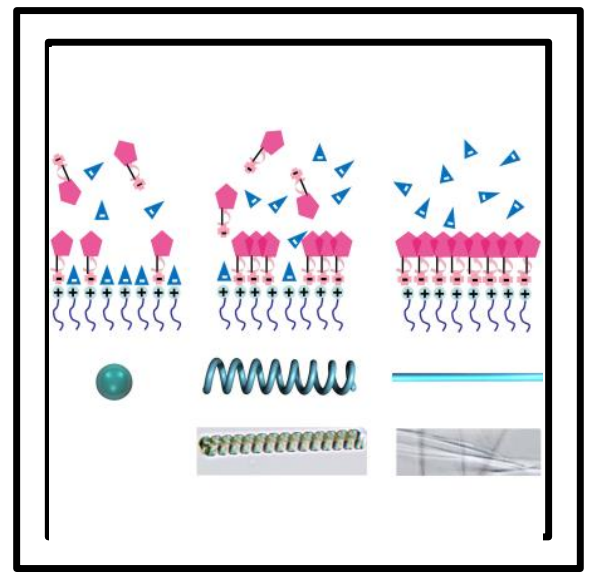

Subtle balance between chiral nucleotides and non-chiral counterions required for hierarchical chirality expression from nucleo-gemini assemblies 